\title{
Uptake of Chloroform by Skin During Short Exposures to Contaminated Water
}

\author{
Mohammad S. Islam, ${ }^{1}$ Luhua Zhao, ${ }^{1}$ James N. McDougal, ${ }^{2}$ and Gordon L. Flynn'
}

Received July 1, 1994

\begin{abstract}
Uptake of chloroform into hairless rat stratum corneum from dilute aqueous solutions was studied using tape-stripping to determine amounts deposited in the skin under various environmental exposure scenarios. The length of exposure of sedated animals to the chloroform-containing medium, the frequency and duration of tape-stripping, and the number of tape-strips per location were varied to map the stratum corneum substantivity of chloroform. Eight minutes immersion of the rat within a well-stirred solution at $36^{\circ} \mathrm{C}$ was found to be adequate time for the gradient to be established fully across the stratum corneum. Penetration was progressively deeper as the exposure time increased. Substantial evaporative loss of chloroform from the aqueous medium of application seem to be responsible for lower cumulative amounts taken up when the same solution was held on the rat's skin within a stainless steel template of fixed area. Of the total uptake $(29 \mathrm{mg})$ from a dilute stirred solution of chloroform $(0.44 \mathrm{mg} / \mathrm{ml})$ at $36^{\circ} \mathrm{C}$, about $95 \%$ was systematically absorbed after a $30 \mathrm{~min}$ exposure as determined by residuals (measurement of bath concentrations).
\end{abstract}

KEY WORDS: Chloroform; skin uptake; skin absorption; hairless rat; tape stripping.

\section{INTRODUCTION}

Concern has been expressed about the cumulative absorption of chemicals from frequent, intermittent, brief exposures to contaminated water, as might occur daily through bathing.(1) For the most part, such exposures fail short of diffusion lag times for permeation of the skin, which range from several minutes for low molecular weight compounds to several hours for heavier ones. ${ }^{(2)}$ In all cutaneous exposures, the stratum corneum acts as a compartment which sorbs a chemical at its outer surface and, over time, diffusionally conducts the chemical to its inner side, where it gains entry to the living tissues and diffuses through these into the blood supply. In short-duration exposures gradients begin to form, but with few molecules reaching the stratum corneum's inner $\operatorname{side}^{(3)}$ during the exposure itself. A great deal of uncertainty exists as to the fate of such surface accu-

\footnotetext{
' College of Pharmacy, The University of Michigan, Ann Arbor, Michigan 48109.

${ }^{2}$ Armstrong Laboratory, WPAFB, Ohio 45433-6573.
}

mulations when exposures are interrupted. Jo et al.(4) estimated the chloroform body burden in healthy individuals taking typical showers. They varied the chloroform concentration from 5 to $37 \mu \mathrm{g} / \mathrm{L}\left(40^{\circ} \mathrm{C}\right)$ while holding the showering time at $10 \mathrm{~min}$. Differences in chloroform concentrations in exhaled breath during normal showering and inhalation-only exposures were used to estimate the extent of dermal absorption. Similarly, Chinery and Gleason ${ }^{(5)}$ and McKone ${ }^{(6)}$ developed models to predict chloroform concentrations in the exhaled breath of human subjects exposed dermally and through inhalation while showering. In studies very like our own, Bogen et al. ${ }^{(7)}$ reported dermal uptake of chloroform after exposing hairless guinea pigs to dilute aqueous solutions (10 to $100 \mu \mathrm{g} / \mathrm{L}$ ) of chloroform in a closed chamber at $32^{\circ} \mathrm{C}$ for 70 minutes. The rate of loss of the chemical from the chamber with and without a guinea pig present was used to estimate the uptake. The method was validated by comparing the urinary and fecal levels of radioactivity obtained after chamber immersion of an animal with that after subcutaneous administration of chloroform in corn oil. Neither Bogen's study nor the 
others mentioned address the fate of chloroform which has built up in the skin during exposure. The present study is focused on this issue.

\section{MATERIALS AND METHODS}

\subsection{Materials and Animals}

Radiolabeled $\left({ }^{14} \mathrm{C}\right)$ chloroform (specific activity - 5 $\mathrm{mCi} / \mathrm{mmol}$ ) was purchased from ICN Biomedicals, Inc. Arvine, California. The neat liquid was diluted with nonradioactive HPLC grade chloroform (Mallincrodt, Inc., St. Louis, Missouri) and stored at $0-4^{\circ} \mathrm{C}$ in a screwcapped glass vial. Deionized water was used to prepare all solutions. Scintillation cocktail (Ecolite ${ }^{+}$) was obtained from ICN Radiochemicals, Covina, California. Tape-stripping was done with $1.9 \mathrm{~cm}$ wide polyester tape (3M No. 850; 3M, St. Paul, Minnesota). Since the animals were anesthetized during the experiments, an isothermal pad (Deltaphase ${ }^{*}$, Braintree Scientific, Inc. Braintree, Massachusetts) provided warmth for an animal while out of the bath. The male hairless rats (CRL: CD) used in the experiments were obtained from Charles River Laboratories, Raleigh, North Carolina. They were 12-20 weeks old, weighing between 350 to $550 \mathrm{~g}$.

\subsection{Bath Assembly for Hairless Rats}

A tall, $1000 \mathrm{ml}$, jacketed glass beaker was used as the bath in which the sedated animal was immersed for a certain period of time. The beaker supported the restraining collar (made of stainless steel) used to keep the animal's head above the water and to isolate the environment around the head from which the animal breathed (Fig. 1). The animal's head was enclosed in a glass chamber formed from a beaker; the rim of this chamber fitted into a cylindrical groove, $66 \mathrm{~mm}$ in diameter, $4 \mathrm{~mm}$ wide and about $2 \mathrm{~mm}$ deep, notched into the collar. Three symmetrically placed notches across the groove allowed fresh air entering through an inlet directly over the animal's head to flow over the head and escape at the level of the neck. In this manner each rat was fed a continuous supply of fresh air to. A porous, circular, stainless steel support was placed at the bottom of the beaker to support the rat and allow a magnetic stirrer to be placed at the bottom of the bath to agitate the water. The bath water temperature was held constant at $36 \pm 0.2^{\circ} \mathrm{C}$ (nominally the skin-surface temperature of the rat) using a circulating water bath (Lauda Model

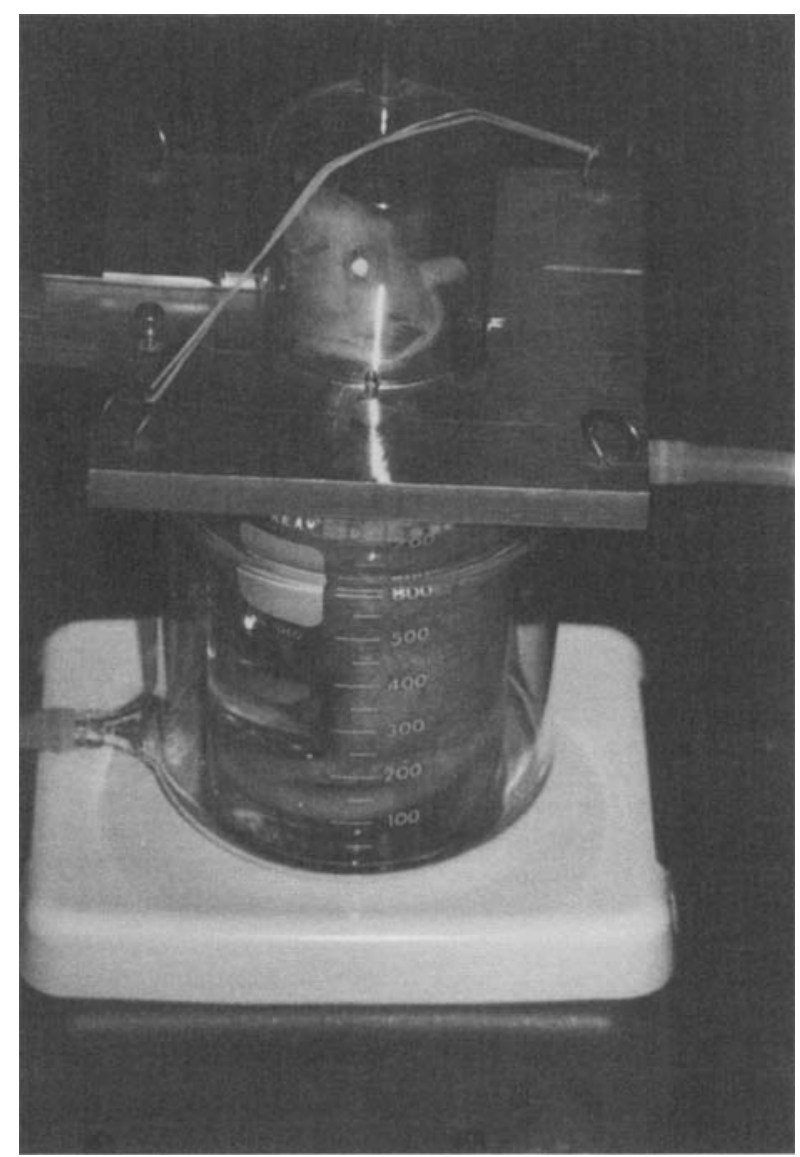

Fig. 1. Bath assembly for immersion experiments with hairless rats.

M3-B). The entire apparatus was placed inside a fume hood to contain all escaping chloroform.

\subsection{Preparation of the Aqueous Solution of Chloroform}

Solutions of chloroform in deionized water at $36^{\circ} \mathrm{C}$ were prepared by adding a calculated volume $(0.205$ $\mathrm{mL}$ ) of chloroform to $450 \mathrm{ml}$ of pre-warmed water in a $1000 \mathrm{ml}$ separatory funnel and then vigorously shaking the water for about 2 minutes. Droplets of chloroform at the bottom of the funnel disappeared within this time. This technique ensured complete solution of the test substance and a reproducible initial concentration of 0.44 $\mathrm{mg} / \mathrm{ml}$. This concentration, three orders of magnitude higher than the upper limit of the U.S. EPA guideline $(0.47 \mu \mathrm{g} / \mathrm{ml}),{ }^{(8)}$ produced detectable levels of chloroform on the skin surface. 


\subsection{Animal Preparation and Exposure to the Bath Water}

A combination of Ketamine hydrochloride $(87$ $\mathrm{mg} / \mathrm{kg}$ ) and Xylazine hydrochloride $(13 \mathrm{mg} / \mathrm{kg}$ ), both given intramuscularly, kept the hairless rats in a sedated state for about 2 hours. Rarely was a supplementary dose required. Small amounts of an emollient ophthalmic ointment were applied to the eyes of each rat to prevent them from drying out during the experimentation. Several areas, $3.8 \mathrm{~cm}^{2}$ each, of the skin on the back of an animal were carefully marked with indelible ink before placing the animal in the bath. Upon its removal, each animal was dried using paper towels and then laid on its belly on absorbent paper covering the heating pad.

\subsection{Use of Templates (for Exposure Times Shorter than 4 Minutes)}

Bath immersion was impractical for very short exposures. Therefore, a rectangular stainless steel template was constructed with an inside area of $10 \mathrm{~cm}^{2}$. This was held firmly against the dorsal surface of the animal with hand pressure and $5 \mathrm{ml}$ of the $0.44 \mathrm{mg} / \mathrm{ml}$ solution of chloroform at $36^{\circ} \mathrm{C}$ were placed within the confines of the template. This solution was left in contact with the skin from 0.5 to $2.0 \mathrm{~min}$.

\subsection{Tape Stripping of the Rat Skin}

\subsubsection{Initial Scenario (20 strips per site; $\approx 55$ sec per strip; 20 min post-exposure interval)}

After exposure, an animal was taken out of the bath or, in case of the template, the chloroform solution was aspirated off the back of the rat and collected in a trap. The exposed area was patted dry with paper toweling. The amount of chloroform in the surface-most tissue was determined by firmly and repeatedly pressing separate pieces of polyester tape (1.9 cm wide and $2 \mathrm{~cm}$ long) onto a marked location for several seconds and then abruptly pulling them away. In preliminary studies 20 tape strippings completely delaminated the stratum corneum as was evident by eventual oozing at the surface. Following its removal, each tape strip was quickly placed inside a scintillation vial containing $15 \mathrm{ml}$ cocktail to minimize evaporation of chloroform. Stripping was begun immediately at one site but delayed $20 \mathrm{~min}$ and $\mathbf{4 0} \mathrm{min}$ at subsequent sites. Radioactivity levels were barely above background after a $\mathbf{4 0}$ min delay.

\subsubsection{Second Scenario (5 tape strips per site; $\approx 10 \mathrm{sec}$} per strip; 5 min post-exposure interval)

It became clear that reduction of the total stripping time was necessary to compress the time for assessing clearance of chloroform from the skin. The interval of stripping between two successive sites was thus shortened from $20 \mathrm{~min}$ to $5 \mathrm{~min}$. Using only 10 seconds per tape to establish good adherence and only five strippings per site reduced the total stripping time at a site from about $19 \mathrm{~min}$ to about $1 \mathrm{~min}$. Complete delamination of the stratum corneum was not obtained for, the animal surface was not moist and glistening at the end of five strippings.

\subsubsection{Third Scenario (5 tape strips per site; 4 sec per strip; 2 min post-exposure interval)}

Chloroform's clearance from the surface of the rat after an exposure was still too rapid to get a handle on using the compressed stripping cycle, necessitating further reduction in the stripping time. The interval from the end of exposure to the beginning of stripping (and that between two successive sites) was shortened from $5 \mathrm{~min}$ to $2 \mathrm{~min}$ and only $4 \mathrm{sec}$ was allowed for adherence of a given strip.

\subsection{Evaporation of Chloroform from the Bath Water}

Chloroform has a high thermodynamic activity in the aqueous test solution and, therefore, appreciable evaporative losses of this solvent from the bath during the course of an experiment was anticipated. To estimate its rate of loss by evaporation and by concurrent uptake into the rat, $250 \mu \mathrm{L}$ aliquots of the bath water were periodically withdrawn and assayed. With a rat inside the beaker, sampling was done for 2 hours. To isolate the evaporative loss only, a screw-capped glass (Type I) bottle roughly comparable in volume and with a neck similar in size to that of the rat was used and, in this case, sampling was done for 6 hours. A $300 \mathrm{ml}$ volume of the test solution gave the same water level as when a rat was inside the beaker. Since the surface area available for evaporation was kept the same in both cases, the difference in the bath chloroform concentrations, after adjusting for the volume difference, was the result of uptake into the rat. 


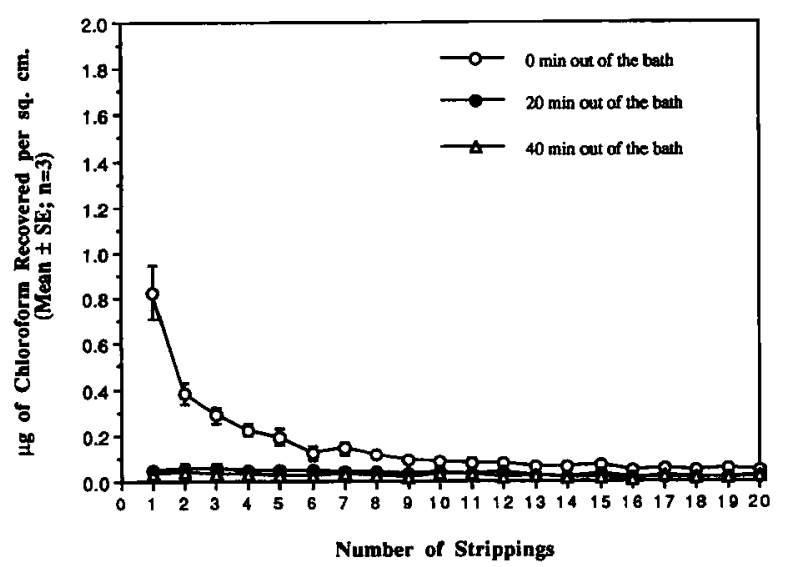

Fig. 2. Amount of chloroform taken up by the stratum corneum as detected by tape stripping ( $20 \mathrm{strips} / \mathrm{site}, \approx 55 \mathrm{sec} / \mathrm{strip}$ ) after exposing hairless rats to contaminated water at $36^{\circ} \mathrm{C}$ for 30 minutes.

\subsection{Statistical Analysis}

One-way Analysis of Variance $(\alpha=0.05)$ and the Student-Newman Keuls (SNK) test (at an experiment wise error rate, $\alpha=0.05$ ) using the General Linear Models Procedure were used to sort out differences in the cumulative uptake of chloroform by stratum corneum as a function of time. ${ }^{\left({ }^{9}\right)}$ Student's $t$-test (one-tailed, $\alpha=0.05$ ) was carried out using the TTEST procedure in situations where the test was deemed applicable.

\section{RESULTS AND DISCUSSION}

\subsection{Tape Stripping of the Rat Skin}

\subsubsection{Initial Scenario (20 strips per site; $\approx 55 \mathrm{sec}$ per strip; 20 min post-exposure interval)}

Figure 2 shows the profiles of chloroform within the layers of the rat stratum corneum after immersing a rat in chloroform-containing water for $30 \mathrm{~min}$ with stripping begun immediately and with delays of 20 and 40 min, respectively. It is evident from the data obtained immediately upon drying the animal that the accumulated amount declines rapidly as the deeper regimes of stratum corneum are harvested. Twenty min following removal of the animal from the bath, little chloroform could be detected in the stratum corneum. Even less chloroform was detectable at $40 \mathrm{~min}$. As the time of exposure was decreased from 15 to $8 \mathrm{~min}$ and then to 4 min, similar profiles were observed upon stripping the

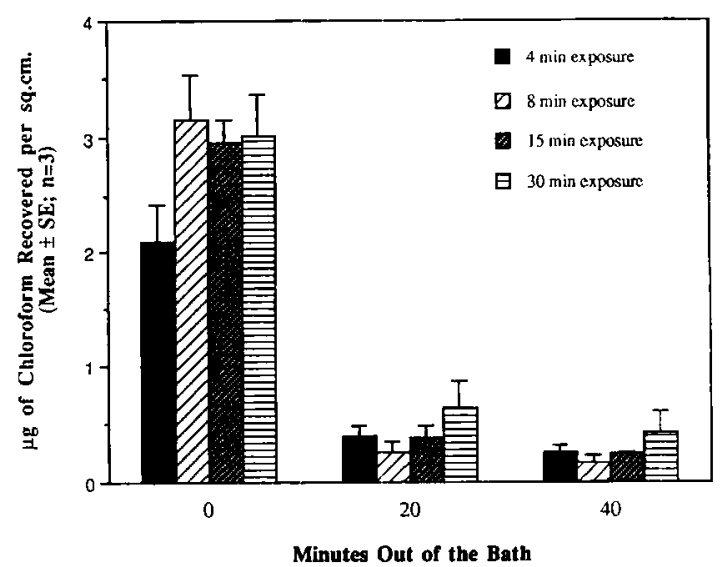

Fig. 3. Cumulative amount of chloroform taken up by the hairless rat's stratum corneum as detected by tape stripping ( 20 strips $/$ site, $\approx 55$ $\mathrm{sec} / \mathrm{strip}$ ) after exposing the animals to contaminated water at $36^{\circ} \mathrm{C}$ for various times.

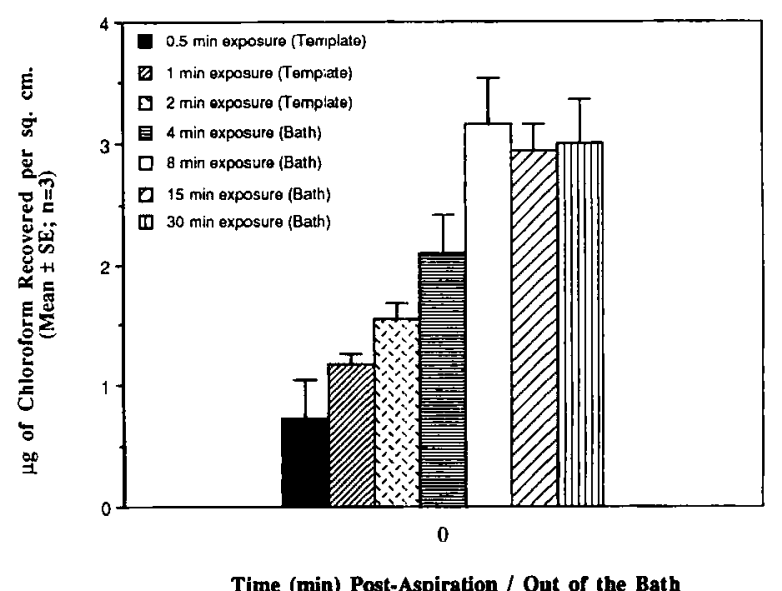

Fig. 4. Cumulative amount of chloroform taken up by the hairless rat's stratum corneum as detected by tape stripping ( 20 strips $/ \mathrm{site}, \approx 55$ $\mathrm{sec} / \mathrm{strip}$ ) after exposing the animals to contaminated water at $36^{\circ} \mathrm{C}$ for various times $(0.5$ to 2 minutes-with template; 4 to 30 minutesinside bath).

animals immediately upon their removal from the bath (data not shown) with the exception that progressively smaller amounts of chloroform were found in the deeper layers of the stratum corneum. Figure 3 depicts the cumulative amounts of chloroform per site picked up by tape stripping at various exposure durations. From the data on stripping begun immediately, it appears that 8 min of exposure is adequate to establish the gradient of chloroform across the skin, and perhaps less, for the cumulative amount collected at $4 \mathrm{~min}$ did not differ statistically from the collections at 8,15 , and $30 \mathrm{~min}$. In Fig. 4 the cumulative amounts recovered after exposing only 


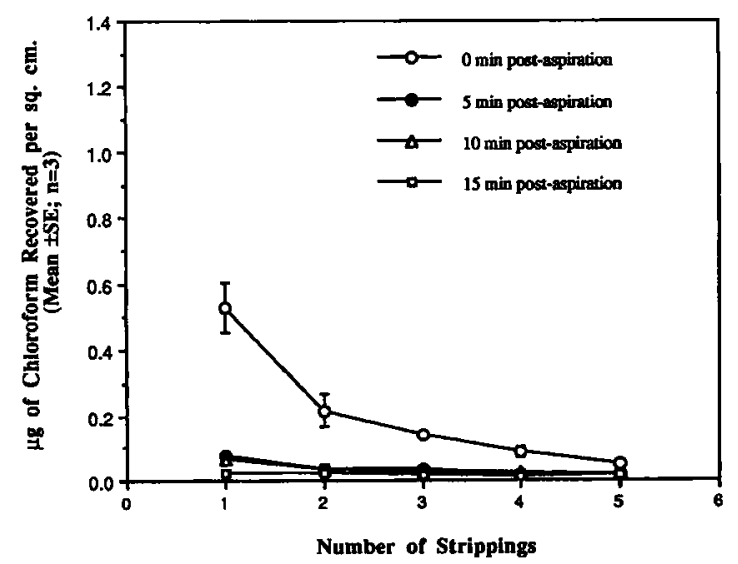

Fig. 5. Amount of chloroform taken up by the stratum corneum as detected by tape stripping ( 5 strips/site, $\approx 10 \mathrm{sec} / \mathrm{strip}$ ) after exposing hairless rats to contaminated water (with template) at $36^{\circ} \mathrm{C}$ for 15 minutes.

$10 \mathrm{~cm}^{2}$ area of a rat for either $0.5,1$, or 2 min are placed alongside the immersion data. Use of the template with quick removal of the solution by aspiration afforded precise control of the shorter exposure times. The cumulative amounts collected ( 0 minute post-aspiration/out of the bath) for $0.5,1$, and 2 min exposures were statistically less than each of those at 8,15 , and $30 \mathrm{~min}$ exposures (SNK test). The amount recovered at $4 \mathrm{~min}$, although not appreciably different from the amounts recovered at 8,15, 30 nor the amounts recovered at 1 and 2 min exposures, was significantly greater than the amount recovered at $0.5 \mathrm{~min}$ (SNK test). However, no statistically supported difference existed among amounts recovered at $0.5,1$, and $2 \mathrm{~min}$ exposures (SNK test). Student's $t$-test revealed that the average of the slopes of the straight lines obtained by plotting the cumulative amounts collected from 0.5 to $8 \mathrm{~min}$ (as in Fig. 5) is significantly greater than $0(p=0.019)$. Despite the lack of statistically supportable differences between some of the times, there is clearly an incremental build up of chloroform in the skin over the first 4 or so minutes. Again, it appears to take from 4 to $8 \mathrm{~min}$ to build up chloroform's gradient.

\subsubsection{Second Scenario (5 tape strips per site; $\approx 10 \mathrm{sec}$ per strip; 5 min post-exposure interval)}

Figure 5 shows profiles of the amounts adsorbed in increasingly deeper layers of the stratum corneum upon exposing a $10 \mathrm{~cm}^{2}$ area of the rat skin to $5 \mathrm{ml}$ of the test solution held stagnant against the animal surface and

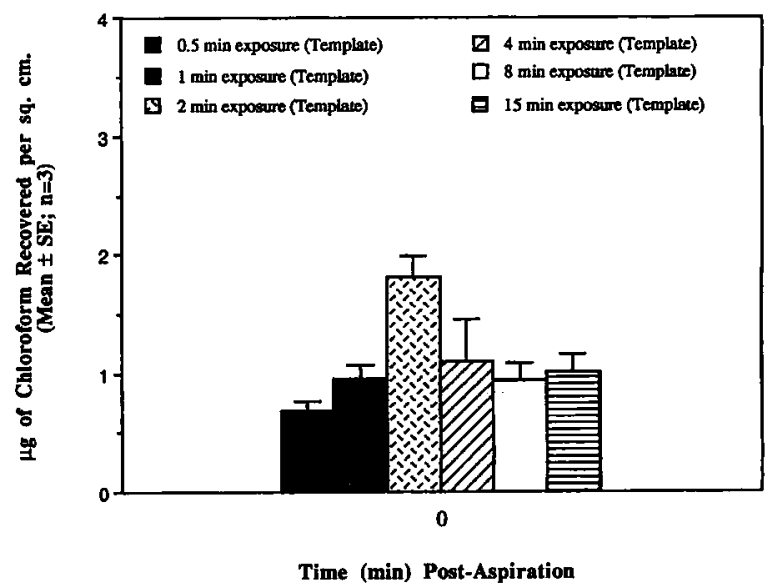

Fig. 6. Cumulative amount of chloroform taken up by the hairless rat's stratum corneum as detected by tape stripping ( 5 strips $/ \mathrm{site}, \approx 10$ sec/strip) after exposing the animals to contaminated water (with template) at $36^{\circ} \mathrm{C}$ for various times.

within the template for 15 minutes. Here, the number of strips per $3.8 \mathrm{~cm}^{2}$ site was set at 5 , the interval between stripping different sites at $5 \mathrm{~min}$ and the time spent per stripping at a site at $10 \mathrm{sec}$. These changes were made to compress the period between stripping of different sites. Clearly there is little substantivity to chloroform. By simply waiting $5 \mathrm{~min}$ after aspiration and towel-drying, the amount of adsorbed chloroform in the first tape strip dropped to a negligible level; after 15 minutes, it was all but imperceptible. Profiles at all other exposure times (not shown) exhibited the same general pattern. Figure 6 depicts the cumulative amount of chloroform taken up by the skin immediately following aspiration and drying at six different short exposure times. The collections at $0.5,1$, and 2 min exposures, while generally lower, do not vary appreciably from the corresponding ones shown in Fig. 4 done using longer times to establish tape adherence and more tape strippings per site. Again we learn that the penetration of chloroform into the upper layers of the stratum corneum is rapid, and it only takes a few minutes for the build-up of the gradient. Figure 6 indicates the cumulative amounts taken up actually decreased at exposure times greater than $2 \mathrm{~min}$. Moreover, the accumulations at 4, 8, and 15 min exposures are significantly lower (Student's $t$-test; $p=0.017,0.002$ and 0.001 , respectively) than the corresponding amounts when the rat was immersed inside the bath with a continuously agitated aqueous solution (Fig. 4). The evaporation of chloroform from the opensurfaced, high area-to-volume applications within the template seems the likely reason for the fall off. Statis- 


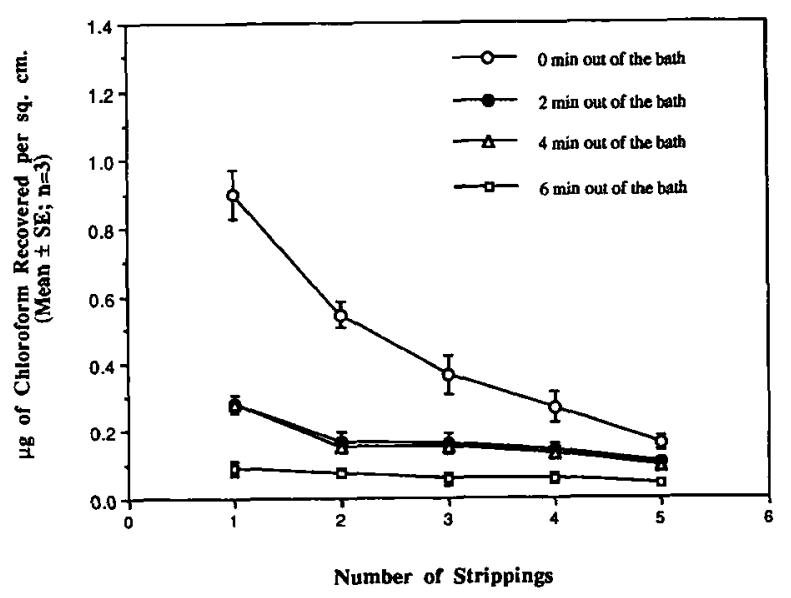

Fig. 7. Amount of chloroform taken up by the stratum corneum as detected by tape stripping ( 5 strips $/$ site, $\approx 4 \mathrm{sec} / \mathrm{strip}$ ) after exposing hairless rats to contaminated water (inside bath) at $36^{\circ} \mathrm{C}$ for 15 minutes.

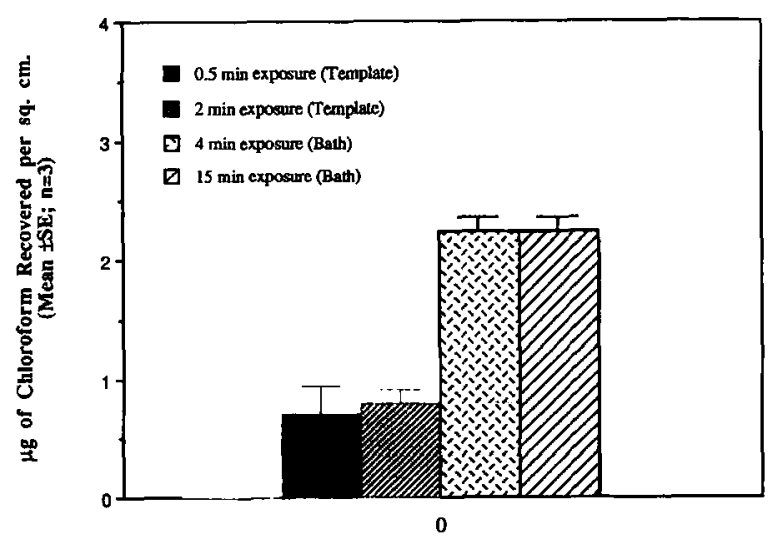

Time (min) Post-Aspiration / Out of the Bath

Fig. 8. Cumulative amount of chloroform taken up by the hairless rat's stratum corneum as detected by tape stripping ( 5 strips/site, $\approx 4$ $\mathrm{sec} / \mathrm{strip}$ ) after exposing the animals to contaminated water at $36^{\circ} \mathrm{C}$ for various times ( 0.5 and 2 minutes-with template; 4 and 15 minutesinside bath).

tically, the cumulative amount recovered at $2 \mathrm{~min}$ stood out from the rest ( $p=0.0001$, ANOVA, and SNK test).

\subsubsection{Third Scenario (5 tape strips per site; 4 sec per strip; 2 min post-exposure interval)}

The stripping interval and the duration of each stripping were further shortened in an attempt to better describe the evaporative loss of chloroform from the stratum corneum in the first moments after exposure. Figure 7 depicts the profiles of the amount of chloroform collected in five tape strippings after immersing a rat in the bath for 15 minutes. Here $4 \mathrm{sec}$ were used to apply the tape to the skin; the interval between stripping of adjacent sites $\left(3.8 \mathrm{~cm}^{2}\right)$ was set at $2 \mathrm{~min}$ and the process was continued up to $6 \mathrm{~min}$. Relative to the zero-time measurements, measurable amounts of chloroform had disappeared from the skin in only $2 \mathrm{~min}$. Evaporation of chloroform back into the atmosphere is almost certainly the predominant factor in this loss, although a degree of systemic absorption too is possible. In this case, very little chloroform was recoverable from the skin if stripping was delayed for only $6 \mathrm{~min}$. At shorter exposure times, 4 min inside the bath and 0.5 and 2.0 min within the template, similar patterns of recovery were observed (not shown), although the distinction(s) between recoveries of chloroform upon delaying stripping more than 2 min were not very sharp. Figure 8 gives the composite picture of the cumulative amount of chloroform taken up by the skin at different exposure times when stripping was begun immediately. The collections at 0.5 and $2 \mathrm{~min}$ exposures are obviously indistinguishable from one another. The same is true for the collections at 4 and 15 $\mathrm{min}$ exposures. However, these pairs, 0.5 and $2 \mathrm{~min}$ and 4 and $15 \mathrm{~min}$, are significantly different from one another (SNK test). These findings suggest that the buildup of the gradient of adsorbed chloroform within the first few (about five) layers of the stratum corneum may be complete as early as in $4 \mathrm{~min}$ when the exposure is to a well-agitated solution of the test substance. Based on the data presented earlier, 4 min exposure may not be quite long enough to establish the equilibrium gradient across the deeper layers of the stratrum corneum.

\subsection{Uptake Measured by Difference in Bath Water Concentrations}

To assess the total uptake of chloroform independently, bath concentrations were measured as a function of time with and without a rat being present. In each case, first-order kinetics was apparent. The average halflife of loss of chloroform from the bath water at $36^{\circ} \mathrm{C}$ with a rat inside was found to be $1.29 \mathrm{~h}$ ( $\pm \mathrm{SE}=0.067$; $n=3$ ), whereas the corresponding value with the bottle present was $2.50 \mathrm{~h}( \pm \mathrm{SE}=0.484 ; n=3)$. The latter actually is $3.72 \mathrm{~h}( \pm \mathrm{SE}=0.688 ; n=3)$ when differences in volumes of bath water in the two experiments are accounted for. From these values one can estimate the amount of chloroform taken up by an animal, a portion of which has to be systematically absorbed, after exposure to a well-stirred aqueous solution of chloro- 
Table I. Extent of Loss from the Bath Water and Uptake of Chloroform into the Hairless Rat After Exposing the Animals to Chloroform-Containing Water at $36^{\circ} \mathrm{C}$ for Various Times ${ }^{a}$

\begin{tabular}{|c|c|c|c|c|c|c|}
\hline $\begin{array}{l}\text { Exposure } \\
\text { time (min) }\end{array}$ & $\begin{array}{c}\% \text { Left } \\
\text { (with rat } \\
\text { inside bath) }\end{array}$ & $\begin{array}{c}\% \text { Left (rat } \\
\text { replaced } \\
\text { with a } \\
\text { bottle) }\end{array}$ & $\begin{array}{c}\% \\
\text { (Adsorbed + } \\
\text { absorbed) } \\
\text { [col.3 - } \\
\text { col.2] }\end{array}$ & $\begin{array}{c}\text { Amount } \\
\text { (mg) } \\
\text { (adsorbed }+^{\text {absorbed) }} \\
\text { (predicted) }^{b}\end{array}$ & $\begin{array}{l}\text { Amount } \\
\text { (mg) } \\
\text { (adsorbed + } \\
\text { absorbed) } \\
\text { (found) }\end{array}$ & $\begin{array}{l}\text { Amount } \\
\text { adsorbed in } \\
\text { the skinc } \\
(\mathrm{mg})\end{array}$ \\
\hline 4 & 93.0 & $\begin{array}{c}96.7 \\
(97.8)\end{array}$ & $\begin{array}{c}3.7 \\
(4.8)\end{array}$ & $\begin{array}{c}3.1 \\
(4.38)\end{array}$ & $\begin{array}{c}7.4 \\
(9.6)\end{array}$ & 1.0 \\
\hline 8 & 90.0 & $\begin{array}{c}94.0 \\
(96.0)\end{array}$ & $\begin{array}{c}4.0 \\
(6.0)\end{array}$ & $\begin{array}{c}6.1 \\
(8.54)\end{array}$ & $\begin{array}{c}8.0 \\
(12.0)\end{array}$ & 1.5 \\
\hline 15 & 85.4 & $\begin{array}{c}92.5 \\
(95.0)\end{array}$ & $\begin{array}{c}7.1 \\
(9.6)\end{array}$ & $\begin{array}{c}10.9 \\
(15.34)\end{array}$ & $\begin{array}{c}14.2 \\
(19.2)\end{array}$ & 1.4 \\
\hline 30 & 76.0 & $\begin{array}{c}86.0 \\
(90.7)\end{array}$ & $\begin{array}{c}10.0 \\
(14.7)\end{array}$ & $\begin{array}{c}19.5 \\
(28.01)\end{array}$ & $\begin{array}{c}19.9 \\
(29.4)\end{array}$ & 1.4 \\
\hline
\end{tabular}

${ }^{a}$ Values in parentheses obtained after correcting for bath water volume (300 $\mathrm{ml}$ used without rat versus 450 $\mathrm{ml}$ with rat).

${ }^{b}$ Calculated using the average first-order rate constants, $0.30 \mathrm{~h}^{-1}(\mathrm{SE}= \pm 0.058 ; n=3)$ [or $0.20 \mathrm{~h}^{-1}(\mathrm{SE}=$ $\pm 0.038 ; n=3)$ after volume correction], and $0.54 \mathrm{~h}^{-1}(\mathrm{SE}= \pm 0.027 ; n=3)$ for the loss of chloroform from the bath water with a glass bottle and a real rat inside, respectively.

c Obtained by extrapolating the amount recovered from the stripping area $\left(3.8 \mathrm{~cm}^{2}\right)$ to the entire exposed surface area calculated using Equation (1).

form for any period of time. Table I presents the results of such calculations.

Assuming that 20 tape-strips per site $\left(3.8 \mathrm{~cm}^{2}\right.$ area) and about $55 \mathrm{sec}$ per tape strip were adequate to completely delaminate the stratum corneum of the hairless rat, a reasonable estimate of the total surface accumulations of chloroform can be made knowing the involved surface area of the rat. The area can be estimated using the following equation ${ }^{(10)}$ :

$$
S=k M_{\mathrm{b}}^{0.67}
$$

where, $S=$ Whole body surface area $\left(\mathrm{cm}^{2}\right), k=$ Meeh coefficient $=9.1$ (for rats), and $M_{b}=$ body mass (g). Since the rat was immersed into the bath water only up to its neck, we are assuming that only $90 \%$ of a rat surface was in contact with the test solution. Taking the average mass of the rats $(414.4 \mathrm{~g} ; n=3)$ used in the $30 \mathrm{~min}$ exposure experiment ( 20 tape strips per site, $\approx 55$ sec per strip), the exposed surface area is estimated to be $464.4 \mathrm{~cm}^{2}$. The amount of chloroform accumulated in the stratum corneum of a rat, using $3 \mu \mathrm{g}$ adsorbed per $\mathrm{cm}^{2}$ (Fig. 3), is about $1.4 \mathrm{mg}$. This is only about $0.7 \%$ of the initial total mass of chloroform in the bath water (200 mg in the $450 \mathrm{ml}$ ). In contrast, the amount of chloroform taken up by a rat by measurement of depletion of chloroform from the bath after a $30 \mathrm{~min}$ exposure is $29.4 \mathrm{mg}$ (Table I). Only $4.8 \%$ of this amount is accounted for by stratum corneum accumulation. Similar low fractions recovered by tape-stripping are obtained in case of 15 and $8 \mathrm{~min}$ exposures to the bath. The amount taken up while a rat was in the bath can be estimated from the evaporation-adjusted first-order rate of loss of chloroform from the bath. The amount actually taken up was also measured at certain times based on bath chloroform contents at the beginning and at the end of each exposure period similarly adjusted for evaporation. It is noteworthy that the kinetic prediction badly underestimates uptakes which were actually measured at shorter exposure times (Table I). This finding simply confirms the theoretical expectation that the uptake of chloroform from the bath water should be faster during the first few minutes as the gradient builds across the skin. Based on our results, a truly first-order uptake process was not actually established until about $\mathbf{3 0}$ minutes into an experiment. When these data are coupled to our tape-stripping findings, it is apparent that over $88 \%$ of the chloroform lost from the bath, after correcting for the evaporative loss, at 4 to $8 \mathrm{~min}$ exposures goes unaccounted for by tape-stripping. Since the loss occurred while the animals were actually immersed, we attribute the unaccounted for loss to systemic absorption.

\subsection{Risk Assessment}

The data in this paper can now be examined relative to the expectations of absorption based on recently developed models for risk assessment. Table II lists equa- 
Table II. Suggested Equations Involved in the Estimation of Amount of Chloroform Dermally Absorbed (Risk Assessment) After Exposure to Its Aqueous Solutions ${ }^{a}$

\begin{tabular}{|c|c|c|c|}
\hline EPA $(1992)^{(11)}$ & McKone and Howd ${ }^{(12)}$ & Cleek and Bunge ${ }^{(13)}$ & This paper \\
\hline $\begin{array}{l}\mathrm{D}_{\mathrm{sc}}=1.98 \times 10^{-10} \mathrm{~cm}^{2} / \mathrm{sec} \\
\text { Eqn. used: } \\
\log \left(\mathrm{D}_{\mathrm{sc}} / \mathrm{l}_{\mathrm{sc}}\right)=-2.72-0.0061 \\
(\mathrm{MW}) ; \mathrm{l}_{\mathrm{sc}}=0.002 \mathrm{~cm}\end{array}$ & $\begin{array}{l}\mathrm{D}_{\text {skin }}=1.77 \times 10^{-9} \mathrm{~cm}^{2} / \mathrm{sec} . \\
\text { Eqn. used: } \\
\mathrm{D}_{\text {skin }}=\mathrm{MW}^{-0.6} \times\left[\left(2.4 \times 10^{-6}\right.\right. \\
\left.+3 \times 10^{-5} \mathrm{~K}_{\text {ow }}{ }^{0.8}\right) /(0.64+0.25 \\
\left.\times \mathrm{K}_{\text {ow }}^{0.8}\right)\end{array}$ & $\begin{array}{l}\mathrm{D}_{\mathrm{c}}=1.69 \times 10^{-10} \mathrm{~cm}^{2} / \mathrm{sec} \\
\text { Eqn. used: } \\
\log \left(\mathrm{D}_{\mathrm{c}} / \mathrm{L}_{\mathrm{c}}, \mathrm{cm} / \mathrm{hr}\right)=-2.8- \\
6.0\left(10^{-3}\right) \mathrm{MW} ; \mathrm{L}_{\mathrm{c}}=0.002 \mathrm{~cm}\end{array}$ & $\begin{array}{l}D_{\mathrm{sc}}=4.38 \times 10^{-10} \mathrm{~cm}^{2} / \mathrm{sec} \\
\text { From the slope of the eqn: } \\
M_{\text {in }} \text { (per unit area) }=2 \mathrm{~K}_{\mathrm{cv}} \mathrm{C}_{\mathrm{v}}{ }^{0} \vee(\mathrm{Dt} / \\
\pi) \text { (using tape-stripping data) }\end{array}$ \\
\hline $\begin{array}{l}\mathrm{K}_{s e} / f_{w}=23.93 \\
\text { Eqn. used: } \\
\log \mathrm{K}_{s c} /_{\mathrm{w}}=0.7 \log \mathrm{K}_{o w}\end{array}$ & $\begin{array}{l}\mathrm{K}_{\mathrm{sw}}=10.06 \\
\text { Eqn. used: } \\
\mathrm{K}_{\mathrm{sw}}=0.64+0.25\left(\mathrm{~K}_{\mathrm{ow}}\right)^{0.8}\end{array}$ & $\begin{array}{l}\mathrm{K}_{\mathrm{cv}}=\mathrm{K}_{\mathrm{cw}}=15.20 \\
\text { Eqn. used: } \\
\log \mathrm{K}_{\mathrm{cw}}=0.60( \pm 0.04) \log \mathrm{K}_{\mathrm{ow}}\end{array}$ & \\
\hline $\begin{array}{l}\mathrm{K}_{\mathrm{p}}=2.48 \times 10^{-6} \mathrm{~cm} / \mathrm{sec} \\
\text { Eqn. used } \\
\log \mathrm{K}_{\mathrm{p}}(\mathrm{cm} / \mathrm{hr})=-2.72+0.71 \\
\times \log \mathrm{K}_{\mathrm{ow}}-0.0061 \mathrm{MW}\end{array}$ & $\begin{array}{l}\mathrm{K}_{\mathrm{p}}=8.90 \times 10^{-6} \mathrm{~cm} / \mathrm{sec} . \\
\text { Eqn. used: } \\
\left.\mathrm{K}_{\mathrm{p}}=\left(\mathrm{K}_{\text {sw }} \mathrm{D}_{\text {skin }}\right) / \delta_{\text {skin }}\right)\end{array}$ & $\begin{array}{l}\mathrm{P}_{\mathrm{cw}}=2.43 \times 10^{-6} \mathrm{~cm} / \mathrm{sec} \\
\text { Eqn. used } \\
\log \mathrm{P}_{\mathrm{cw}}(\mathrm{cm} / \mathrm{hr})=-2.8( \pm 0.08) \\
-6.0( \pm 0.6) \times\left(10^{-3}\right)(\mathrm{MW}) \\
+0.74( \pm 0.07) \log \mathrm{K}_{\mathrm{ow}}\end{array}$ & $\begin{array}{l}\text { When used the eqn: } \\
P_{c v}=\left(K_{c v} D_{c}\right) / L_{c} \text {, the value for } P_{c v} \\
=P_{c w}=3.33 \times 10^{-6} \mathrm{~cm} / \mathrm{sec} .\left(L_{c}=\right. \\
\left.0.002 \mathrm{~cm}, D_{c} \text { is experimental }\right)\end{array}$ \\
\hline $\begin{array}{l}\tau=56.12 \text { min. } \\
\text { Eqn. used } \\
\tau=1_{s c}^{2} / 6 D_{s c}\end{array}$ & $\begin{array}{l}\tau=6.28 \mathrm{~min} \\
\text { Eqn. used } \\
\tau=\delta_{\text {skin }}^{2} / 6 \mathrm{D}_{\text {skin }}\end{array}$ & $\begin{array}{l}\tau=t_{\text {exp }} D_{c} / L_{c}^{2} \text { is the normalized } \\
\text { exposure time, not the lag time. }\end{array}$ & $\begin{array}{l}\tau \approx 4 \min .4 \leq \tau \leq 8 \min \text { (experi- } \\
\text { mental) }\end{array}$ \\
\hline $\begin{array}{l}\mathrm{t}^{*}=134.68 \mathrm{~min} \\
\text { Eqn. used: } \\
\mathrm{t}^{*}=2.4 \mathrm{\tau}\end{array}$ & & $\begin{array}{l}\mathrm{t}^{*}=157.2 \mathrm{~min} \\
\text { Eqn. used: } \\
\mathbf{t}^{*}=0.4 \mathrm{~L}_{\mathrm{c}}{ }^{2} / \mathrm{D}_{\mathrm{c}}\end{array}$ & $\begin{array}{l}\mathrm{t}^{*}=9.6 \mathrm{~min} . \\
\text { Eqn. used: } \\
\mathrm{t}^{*}=2.4 \tau(\tau \text { being experimental })\end{array}$ \\
\hline $\begin{array}{l}\mathrm{DA}_{\text {event }}\left(\mathrm{mg} / \mathrm{cm}^{2} / \text { event }\right)=2 \mathrm{~K}_{\mathrm{p}} \mathrm{C}_{\mathrm{v}} \\
\sqrt{ }\left[\left(6 \tau \mathrm{t}_{\text {even }}\right) / \pi\right]\end{array}$ & $\begin{array}{l}\text { (a) } \mathrm{AR}_{\text {water }}\left(\mathrm{mg} / \mathrm{cm}^{2} \text { per } \mathrm{mg} / \mathrm{cm}^{3}\right) \\
=\left(\delta_{\text {skin }} \mathrm{K}_{\text {sw }}\right) / 2 \text {, when } \mathrm{t}_{\text {event }}<\tau \text {. } \\
\text { (b) } \mathrm{AR}_{\text {water }}=\left(\delta_{\text {skin }} \mathrm{K}_{\text {sw }}\right) / 2+\left(\mathrm{t}_{\text {event }}\right. \\
-\tau) \times \mathrm{K}_{\text {sw }} \times \mathrm{D}_{\text {skin }} / \delta \text { skin, when } \\
\mathrm{t}_{\text {event }}>\tau\end{array}$ & $\begin{array}{l}M_{\text {in }} / A=2 C_{v}{ }^{0} K_{c v} V\left[\left(D_{c} t_{e x p}\right) / \pi\right] \\
\text { if } t_{\text {exp }} \leq t^{*}\end{array}$ & \\
\hline
\end{tabular}

\footnotetext{
a Diffusion Coefficient in the stratum corneum is symbolized by $\mathrm{D}_{\mathrm{sc}}{ }^{(11}$. This Paper), $\mathrm{D}_{\text {skin }}{ }^{(12)}$ and $\mathrm{D}_{\mathrm{c}}^{(13)}$; Stratum Corneum/Water Partition Coefficient is symbolized by $\mathrm{K}_{\mathrm{se}} /{ }_{\mathrm{w}}{ }^{(1)}, \mathrm{K}_{\mathrm{sw}}{ }^{(12)}$ and $\mathrm{K}_{\mathrm{cw}}$ (or $\left.\mathrm{K}_{\mathrm{cv}}\right)^{(13) ;}$;tratum Corneum Thickness is symbolized by $\mathrm{l}_{\mathrm{sc}}{ }^{(11)}$, $\delta_{\mathrm{skin}}{ }^{\left({ }^{(2)}\right.}$ and $\mathrm{L}_{\mathrm{c}}{ }^{(13)}$; Permeability Coefficient is symbolized by $\mathrm{K}_{\mathrm{p}}^{(11,12)}, \mathrm{P}_{\mathrm{cw}}{ }^{(13)} ; \mathrm{\tau}$ is the lag time; $\mathrm{t}^{*}$ is the Time to Reach the Steady-State; Mass Absorbed per Unit Area is symbolized by $D A_{\text {event }}{ }^{(1)}$ and $M_{i n} / A^{(13)}$, whereas $A R_{\text {water }}^{(12)}$ expresses the ratio of the Absorbed Dose (per Event) per Unit Area to the Exposure Medium Concentration.
}

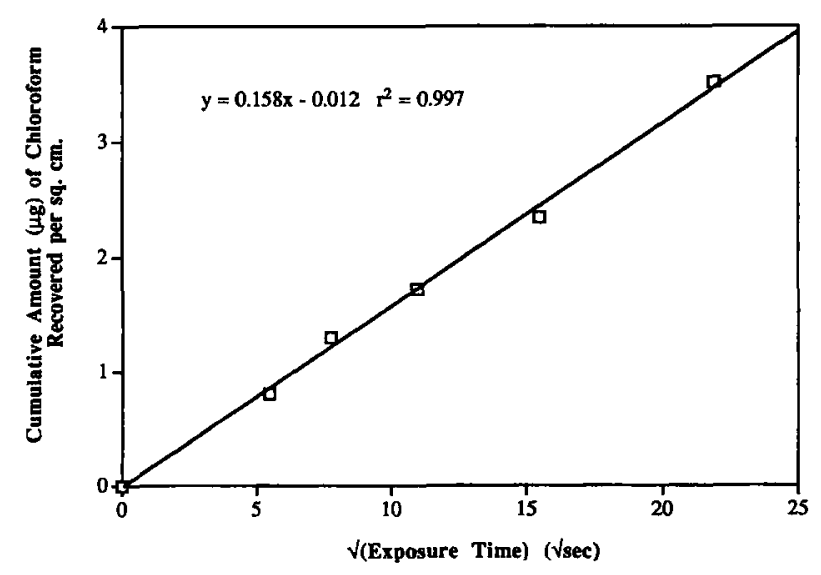

Fig. 9. Estimation of the diffusion coefficient of chloroform in the hairless rat's stratum corneum from the data (up to $8 \mathrm{~min}$ ) used in Fig. 4.

tions forwarded for estimating the amounts of organic chemicals dermally absorbed upon exposures to aqueous solutions, including ancillary information needed to use the equations. The table also compares the application of the published equations with the results obtained in this study (last column). We discovered that a plot of the cumulative amount of chloroform $(\mu \mathrm{g})$ found by tape stripping is proportional to the square root of exposure time up to $8 \mathrm{~min}$ (Fig. 9). The slope of this plot yields an estimate of the diffusion coefficient of chloroform within the stratum corneum of $4.38 \times 10^{-10} \mathrm{~cm}^{2} / \mathrm{sec}$. This estimate of the diffusion coefficient falls in the middle of the range of values calculated using the published methods of estimation (first row, Table II), considering everything a surprisingly tight agreement. Model predictions of the amounts of chloroform absorbed are not in good agreement with our experimental observations, however. These estimates are listed side-by-side the experimental evaluations in Table III for exposure times extending to $30 \mathrm{~min}$. It can be seen that the model-based estimations, especially that by Cleek and Bunge, ${ }^{(13)}$ give a reasonable accounting of the chloroform found in the 
Table III. Comparison of the Amount (mg) of Chloroform Dermally Taken up by the Hairless Rat (over $464.4 \mathrm{~cm}^{2}$ ) as Estimated by Using Different Equations

(Table II) with the Found Values

\begin{tabular}{cccccc}
\hline $\begin{array}{c}\text { Exposure } \\
\text { time (min) }\end{array}$ & $\begin{array}{c}\text { EPA } \\
(1992)^{(11)}\end{array}$ & $\begin{array}{c}\text { McKone and } \\
\text { Howd }^{(12)}\end{array}$ & $\begin{array}{c}\text { Cleek and } \\
\text { Bunge }^{(13)}\end{array}$ & $\begin{array}{c}\text { This paper } \\
\text { (total uptake } \\
\text { found) }^{2}\end{array}$ & $\begin{array}{c}\text { This paper } \\
\text { (only skin } \\
\text { uptake) }\end{array}$ \\
\hline 4 & 1.26 & 2.06 & 0.71 & 9.6 & 1.0 \\
8 & 1.78 & 2.24 & 1.00 & 12.0 & 1.5 \\
15 & 2.44 & 3.01 & 1.37 & 19.2 & 1.4 \\
30 & 3.45 & 4.65 & 1.93 & 29.4 & 1.4 \\
\hline
\end{tabular}

${ }^{a}$ Values adjusted for differences in bath water volume $(450 \mathrm{ml}$ with and $300 \mathrm{ml}$ without a rat inside).

stratum corneum by tape stripping, but all others seriously underestimate the total uptake. Moreover, those equations are based on $t^{*}$, the time needed to reach a steady-state, and this was much longer than our experimental value of less than $10 \mathrm{~min}$ except for the estimation of method of McKone and Howd.(12) Also, the equation proposed by Cleek and Bunge ${ }^{(13)}$ found in Table III is intended to estimate adsorption into the stratum corneum as if it were a semi-infinite medium. Our data suggest it does this if one discounts the amount systemically absorbed. The total uptake found (Table III) in our laboratory indicates a significant amount of chloroform reaches the viable epidermis and its underlying systemic circulation with exposure times as low as 4 min. Although currently we are unable to quantify the amount of such a volatile compound as chloroform in the viable epidermis, ongoing pharmacokinetic experiments in our lab with the same dermal exposure scenarios will assess the systemic levels of this compound.

\section{CONCLUSIONS}

This work shows the gradients of low molecular weight, hydrophobic pollutants are surprisingly rapidly established across the skin of a rat. Therefore, the past practice of assuming steady-state kinetics for short exposures may not depart all that far from reality for such compounds, at least when the exposure times are measured in tens of minutes. It is doubtful that this is also true for larger compounds which have low and often times immeasurable vapor pressures and it is impossible to say, at this time, whether it is true for polar compounds which also tend to have high molecular cohesiveness and low vapor pressures. From this research it is clear that evaporation quickly clears the skin of volatile compounds like chloroform and thus, for com- pounds as this, exposure stops almost as soon as the contact with the medium of exposure is ended.

\section{ACKNOWLEDGMENTS}

Funding for this project was provided by the United States Department of the Air Force, F33615-91-C-0540.

\section{REFERENCES}

1. A. L. Bunge, G. L. Flynn, and R. H. Guy, "Predictive Model for Dermal Exposure Assessment," in R. G. M. Wang (ed.), Water Contamination and Health (Mercel Dekker, New York, 1994).

2. G. L. Flynn, "Physicochemical Determinants of Skin Absorption," in T. R. Gerrity and C. J. Henry (eds.), Principles of Routeto-Route Extrapolation for Risk Assessment (Elsevier Science Publishing Company, New York, 1990).

3. J. Crank, The Mathematics of Diffusion (Clarendon Press, Oxford, UK, 1975).

4. W. K. Joe, C. P. Weisel, and P. J. Lioy, "Routes of Chloroform Exposure and Body Burden from Showering with Chlorinated Tap Water," Risk Analysis 10(4), 575-580 (1990).

5. R. L. Chinery and A. K. Gleason, "A Compartmental Model for the Prediction of Breath Concentration and Absorbed Dose of Chloroform After Exposure While Showering,' Risk Analysis 13(1), 51-62 (1993).

6. T. E. McKone, "Linking a PBPK Model for Chloroform with Measured Breath Concentrations in Showers: Implications for Dermal Exposure Models," J. Expo. Anal. Environ. Epidemiol. 3(3), 339-365 (1993).

7. K. T. Bogen, B. W. Colston, and L. K. Machicao, "Dermal Absorption of Dilute Aqueous Chloroform, Trichloroethylene, and Tetrachloroethylene in Hairless Guinea Pigs," Fund. Appl. Toxicol. 18, 30-39 (1992).

8. U.S. Environmental Protection Agency (EPA), "National Organic Monitoring Survey," Tech. Supp. Div. Off. of Water Supply, Cincinnati, Ohio (1977).

9. SAS, version 6.08, SAS Institute Inc., SAS Campus Drive, Cary, North Carolina.

10. K. Schmidt-Nielsen, Scaling: Why Is Animal Size so Important? (Cambridge University Press, Cambridge, UK, 1984).

11. U.S. Environmental Protection Agency (EPA), "Dermal Exposure Assessment: Principles and Applications," Report No. EPA/600/8-91/011B, Office of Health and Environmental Assessment, U.S. EPA, Washington, D.C. 20460 (1992). 
12. T. E. McKone and R. A. Howd, "Estimating Derrmal Uptake of Nonionic Organic Chemicals from Water and Soil. Part 1. Unified Fugacity-based Models for Risk Assessments," Risk Analysis 12, $543-557$ (1992).
13. R. L. Cleek and A. L. Bunge; "A New Method for Estimating Dermal Absorption from Chemical Exposure. 1. General Approach," Pharm. Res. 10(4), 497-506 (1993).

14. R. O. Potts and R. H. Guy, "Predicting Skin Permeability," Pharm. Res. 9, 663-669 (1992). 